\title{
El principio de Servicio objetivo a los intereses generales y su control por los tribunales
}

\author{
Juan A. Ureña Salcedo \\ Profesor titular de Derecho Administrativo. Universidad de Valencia \\ Juan.A.Urena@uv.es
}

\begin{abstract}
Resumen
Estamos ante una aproximación a la justificación del Poder Ejecutivo y al control que de la actividad administrativa ejerce el Poder Judicial, a partir de las declaraciones constitucionales de los artículos 103 y 106. Caemos de bruces en cuestiones como la definición de los intereses generales por la Administración y la revisión del ejercicio de potestades discrecionales por Jueces y Magistrados.
\end{abstract}

Palabras clave Poder ejecutivo; discrecionalidad administrativa; motivación; control judicial.

\section{The principle of objetive Service in the general interest and its control by the courts}

\begin{abstract}
We are witnessing an approximation to the justification of the Executive Power and to the control of administrative action exercised by the Judicial Power, based on the constitutional declarations of articles 103 and 106. We stumble over questions like the definition of the general interests by the Administration and the revision of the exercise of discretionary powers by judges and magistrates.
\end{abstract}

Key words

Executive power; administrative discretion; statement of reason; judicial control. 


\section{LA JUSTIFICACIÓN DE LA ADMINISTRACIÓN PÚBLICA}

La justificación última del poder público siempre ha sido la consecución del bien común, del interés público o del interés general'. Cicerón, haciendo suyas las palabras de Catón, decía que los gobernantes debían defender los intereses de los ciudadanos (olvidándose del propio provecho), velando por todo el cuerpo de la República². John Locke sostuvo que el poder público estaba limitado a procurar el bien público de la sociedad ${ }^{3}$. Rousseau, en fin, por poner otro ejemplo, defendió que con el contrato social se perseguía el bien general.

En nuestros días y en nuestro país el fin constitucional que justifica y legitima la existencia de la Administración es, de acuerdo con el artículo 103.1 CE, el servicio objetivo a los intereses generales. La Administración Pública tiene carácter servicial4.

$1 \quad$ Nieto, A., "La Administración sirve con objetividad los intereses generales", Estudios sobre la Constitución española. Homenaje al Profesor Eduardo García de Enterría, T. III, Civitas, Madrid, 1991, p. 2186, recuerda que "los intereses generales han preocupado a la cultura política desde Platón, la bibliografía que han producido es ingente y, en último extremo, constituye una de las piedras angulares de la democracia y del Derecho público antiguo y moderno". En dicho trabajo, no obstante, se da cuenta de las principales ideas de muchos de los autores que se han ocupado de estas cuestiones. Sobre el poder, en fin, basta con recordar que García-Pelayo, M., Los mitos políticos, Alianza Editorial, Madrid, 1981, p. 38, sostuvo que "el hombre ha tratado constantemente de eludir, neutralizar o de sublimar el hecho radical y terrible de estar sometido a otro hombre (...) y como el poder ha de ejercerse por el hombre, resulta, entonces, que hay que dar a ese hecho un sentido o una forma que lo transfigure hasta hacerle perder su carácter de dominación interhumana. En el desarrollo de esta pretensión, la historia del pensamiento político ha creado unas fórmulas de transfiguración que, valederas para unas situaciones históricas, se convierten en inoperantes para otras, al descubrirse que tras ellas sigue ocultándose el aborrecido poder del hombre sobre el hombre,y, entonces, otras fórmulas han de venir a cubrir el vacío abierto por la falta de convicción en las existentes".

2 Cicerón, De Officiis, Sobre los deberes, traducción, introducción y notas de José Guillén Cabañero, Alianza editorial, Madrid, 2001, p. 101, dice que "los que hayan de gobernar el Estado deben tener simpre muy presentes estos dos preceptos de Catón: el primero defender los intereses de los ciudadanos de forma que cuanto hagan lo ordenen a ellos, olvidándose del propio provecho; el segundo, velar sobre todo el cuerpo de la República, no sea que, atendiendo a la protección de una parte, abandonen a las otras". Añade que "no hay, pues, vicio más repugnante -para volver a nuestro tema- que la avaricia, sobre todo en la gente principal y en los que gobiernan la República. Desempeñar un cargo público para enriquecerse no es solamente vergonzoso, sino también impío contra la patria y sacrílego contra los dioses" (p. 103).

3 Locke, J., The Second Treatise of Civil Government. An Essay Concerning the True Original, Extent and End of Civil Government, (1690). Cito por Segundo Tratado sobre el Gobierno Civil. Un ensayo acerca del verdadero origen, alcance y fin del Gobierno Civil, traducción, prólogo y notas de Carlos Mellizo, Alianza Editorial, Madrid, quinta reimpresión 2008, pp. 134-138, y 143. Dice, literalmente, que "no puede suponerse que criatura racional alguna cambie su situación con el deseo de ir a peor. Y por eso, el poder de la sociedad o legislatura constituida por ellos no puede suponerse que vaya más allá de lo que pide el bien común (...) todo esto no debe estar dirigido a otro fin que no sea el de lograr la paz, la seguridad y el bien del pueblo (...) El poder de los legisladores, aun en su máximo grado, está limitado a procurar el bien público de la sociedad". Para este pensador, como es bien sabido, los hombres deciden mermar su libertad por razones de seguridad, para preservar su propiedad, para que los conflictos con otros hombres se resuelvan, según las leyes establecidas, por jueces públicos e imparciales, y para que dichas sentencias puedan ser ejecutadas debidamente.

4 Rousseau, J.-J., Du Contrat Social, (1762), edición de Pierre Burgelin, Garnier-Flammarion, Paris, 1966, p. 140, afirmaba que "les dépositaires de la puissance exécutive ne sont point les maîtres du peuple mais ses officiers". 
Sirve "con objetividad los intereses generales y actúa de acuerdo con los principios de eficacia, jerarquía, descentralización, desconcentración y coordinación con sometimiento pleno a la ley y al Derecho". Los intereses generales son, como siempre han sido, una de las claves de bóveda del sistema5.

\subsection{Al servicio de los intereses generales}

La Administración está al servicio de los intereses generales. La pluralidad y confusión de intereses existente en las sociedades y en los Ordenamientos del siglo XXI, sin embargo, debe apuntarse antes de seguir avanzando. Suena incluso desfasado, en pleno debate sobre la dialéctica entre intereses de la Unión Europea e intereses de los Estados miembros, tener que repetir que tan general y público es el interés que persigue el Estado como el que persiguen las Comunidades Autónomas, como en más de una ocasión ha tenido que recordar el Tribunal Constitucional ${ }^{6}$.

Es bien sabido, además, que con el Estado social se produjo una evidente confusión entre interés público y privado en las normas jurídicas. La persecución del interés general dejó de ser interpretada como algo exclusivo del poder público. A nadie extraña en la actualidad la existencia de personas jurídicas privadas que realizan actividades de interés general y que, precisamente por ello, gozan de privilegios propios de las Administraciones públicas. La valoración que se encuentra detrás de las muy variadas decisiones que adopta la Administración, en efecto, no siempre supone una contraposición entre interés público e interés privado, entre interés general e interés individual o particular. El carácter social del Derecho supuso la superación, para algunos maniquea, entre interés público e interés privado. Baste con recordar, al margen de que A. Smith ya defendiese que cuando el individuo persigue su interés particular está persiguiendo también simultáneamente el interés general7, la aparición de intereses colectivos y difusos o, insistimos, la infinidad de personas privadas que con su actuación satisfacen fines de interés general ${ }^{8}$.

5 Sánchez Morón, M., “Artículo 103 CE”, en Comentarios a la Constitución Española, XXX aniversario, María Emilia Casas Baamonde y Miguel Rodríguez-Piñero y Bravo-Ferrer (Directores), Fundación Wolters Kluwer, Madrid, 2009, p. 1682 y siguientes.

6 Cosa distinta parece que ocurre en la práctica con el interés municipal, sometido a los intereses supramunicipales. La discusión remite, por supuesto, al debate sobre la distinción entre autonomía política y autonomía administrativa; a las competencias que la Constitución y las leyes reconocen al Estado y a las Comunidades Autónomas, a la tutela que ambos pueden ejercer sobre las entidades que integran la Administración local. Tampoco se trata de un tema novedoso. Véase, por todos, Constant, B., Principes de politique applicables à tous les governements représentatifs et particulièrement à la Constitution actuelle de la France (1815), Cito aquí por Escritos políticos, estudio preliminar, traducción y notas de María Luisa Sánchez Mejía, Centro de Estudios Constitucionales, Madrid, 1989, p. 123.

7 Tomo la cita, por lo demás bien conocida, de Nieto, A., “La Administración sirve con objetividad...", cit., p. 2200.

8 Piénsese en las entidades de configuración legal que persiguen fines de interés general, en las Fundaciones públicas y privadas, y en lo que se ha dado en llamar Tercer Sector, pero también en la colaboración de privados en el ejercicio de funciones públicas. Hay muchas empresas, sean o no concesionarias de servicios públicos, que con su actividad satisfacen fines de interés general. 
En el s. XXI, dicho abiertamente, no siempre resulta fácil la contraposición entre intereses generales e intereses particulares. Ni que el interés público pueda imponerse por la Administración, siempre y en todo caso, al interés privado (a algunos derechos de los ciudadanos, si así se prefiere). La ponderación de intereses y derechos en el caso concreto resulta inevitable9. Incluso el Código europeo de buena conducta administrativa (aplicable a la Administración europea), reconoce expresamente que debe haber un justo equilibrio entre los intereses individuales y el interés público. Esta apasionante discusión sobre el interés general y el interés particular, evidentemente, tiene una vertiente procesal en la que, al menos de momento, no vamos a entrar ${ }^{10}$.

Los intereses generales que justifican la existencia del poder público y a los que debe servir objetivamente la Administración de nuestros días, sea como fuere, deben concretarse, en primer lugar, en las normas jurídicas.

\subsection{La concreción de los intereses en las normas jurídicas}

La Constitución que, si dejamos a un lado todas las consecuencias de la globalización y de la integración europea, es la principal norma jurídica en el plano interno, debería ser la norma que definiese, en la medida de lo posible, los intereses generales ${ }^{11}$. En la Norma Fundamental de 1978, de hecho, pueden encontrarse algunas referencias a los intereses generales que debe perseguir la acción pública. En muchas ocasiones, sin embargo, el constituyente tuvo que conformarse con redactar normas de carácter programático o finalista, con fijar objetivos que pudiesen alcanzarse de formas distintas. Corresponde al Poder Legislativo, en consecuencia, determinar muchos de esos intereses generales y decidir el mejor modo de alcanzarlos ${ }^{12}$. Los

9 Nieto, A., “La Administración sirve con objetividad...”, cit., p. 2209. Baño León, J.M., Derecho urbanístico común, lustel, 2009, p. 95 y siguientes, se refiere a la "ponderación razonable del interés local” en los proyectos de ordenación y obras del Estado y de las Comunidades Autónomas. Ortega, L., De la Sierra, S., (coords.), Ponderación y Derecho Administrativo, Marcial Pons, Madrid, 2009.

10 Travi, A., Lezioni di Giustizia Amministrativa, G. Giappichelli Editore, Torino, 2010, p. 49 y siguientes, recuerda el debate sobre la distinción entre interés legítimo y derecho subjetivo, y el acuerdo en la doctrina italiana sobre la inexistencia de derechos subjetivos cuando del ejercicio de una potestad discrecional se trata. Recuerda, no obstante, que tras una resolución de la Corte de casación de 22 de julio de 1999 se ha reconocido que la lesión de un interés legítimo puede dar lugar a un resarcimiento de daños. En la p. 54 afirma que "In passato il potere dell'Amministrazione è stato considerato spesso come un valore che esprimeva la supremazia dello Stato e dei suoi fini rispetto al cittadino: questa lógica però è radicalmente incompatible con i principi di un ordinamento democrático".

11 Nieto, A., El desgobierno de lo público, Ariel, Barcelona, 2008, p. 232 y siguientes, tras reconocer que "intereses generales serán los que en cada caso declare un poder público, sea el legislativo, el ejecutivo o el judicial", añade, como es obvio, que la referencia a los intereses generales cumple "una mera función ideológica de legitimación del poder”. A los intereses generales como ideología y como límite del poder también se refirió en "La Administración sirve con objetividad...”. cit., p. 2209 y siguientes. También puede verse, entre muchísimos otros, Embid Irujo, A., “La relación entre los poderes del Estado en la reciente dogmática alemana”, RAP, n. ${ }^{\circ} 115$, enero-abril, 1988.

12 Una mínima referencia bibliográfica sobre la Constitución como norma jurídica y las normas programáticas puede verse en Ureña Salcedo, J. A., "Comentario al artículo 130 de la Constitución. El 
legisladores, que se han multiplicado estos últimos años, sin embargo, tampoco pueden preveerlo todo. Las leyes, que de acuerdo con Rousseau debían ser expresión del interés común ${ }^{13}$, algunas veces dejan un margen de libertad en manos del Gobierno o de la Administración para satisfacer el concreto interés público de que se trate. Algunas leyes, no todas, se limitan a establecer los objetivos a conseguir con una determinada política pública, dejando gran libertad a la Administración para detallar los procedimientos y para adoptar las decisiones que resulten más adecuadas para alcanzarlos ${ }^{14}$.

La Ley no puede preveerlo todo. Resulta innecesario utilizar términos propios para algo que hace siglos que es bien sabido. Locke ya mantuvo a finales del S. XVII que "allí donde el poder legislativo y el ejecutivo residen en manos distintas -como ocu-

Estado Social y los mandatos a los poderes públicos", en Comentarios a la Constitución Española, XXX aniversario, María Emilia Casas Baamonde y Miguel Rodríguez-Piñero y Bravo-Ferrer (Directores), Fundación Wolters Kluwer, Madrid, 2009. El debate sobre la flexibilidad o la rigidez de las constituciones pasa por ser, evidentemente, un tema clásico. Piénsese ahora en las recientes modificaciones del Tratado de Funcionamiento de la Unión Europea o en las del artículo 135 CE. Rousseau, J.-J., Du Contrat Social, cit., p. 141, apostaba por la posibilidad de reformar el pacto social. Decía que “il n y a dan l’État aucune loi fondamentale qui ne se puisse révoquer, non pas même le pacte social; car si tous les citoyens s'assemblaient pour rompre ce pacte d'un commun accord, on ne peut douter qu'il ne fût très légitimement rompu".

13 Rousseau, J.-J., Du Contrat Social..., cit.,p. 127, defendió que la voluntad general se imponía prácticamente sin condiciones sobre el interés particular. Advertía del riesgo, no obstante, de que se confundiese voluntad general, que tiende a satisfacer el interés común, con voluntad particular e interés privado de un determinado colectivo o grupo. El pensador ginebrino se refiere al abuso del gobierno, a la usurpación del poder soberano, "je veux dire que le gran État se dissout et qu'il s'en forme un autre dans celui-la, composé seulement des membres du gouvernement et qui n'est plus rien au reste du peuple que son maître et son tyran. De sorte qu 'à l'instant que le gouvernement usurpe la souveraineté, le pacte social est rompu, et tous les simples citoyens, rentrés de droit dans leur liberté naturelle, sont forcés mais nos pas obligés d'obéir". Benjamin Constant, Principes de politique applicables..., cit., p. 122, comparte con Rousseau la idea de que el principio de soberanía popular supone la supremacía de la voluntad general sobre cualquier voluntad particular. Defiende, no obstante, como es bien sabido, la existencia de esferas individuales que no pueden ser invadidas por nadie, pues "quedan fuera de toda competencia social". Advierte del peligro que supone que sean los gobiernos los que dicten la voluntad general, e insiste en la existencia de derechos y libertades de los ciudadanos que no pueden ser violados, que la soberanía, en definitiva, es limitada. Para Constant, hay que insistir en ello, "lo que se relaciona únicamente con el individuo, no debe someterse más que al individuo. Nunca se repetirá bastante que la voluntad general no es más respetable que la voluntad particular, cuando sale de su efera". John Stuart Mill, como antes von Humboldt, y antes y después muchísimos otros, insistirían en estas mismas ideas. Para John Stuart Mill, Considerations on Representative Government, (1861), cito por Consideraciones sobre el gobierno representativo, traducción y prólogo de Carlos Mellizo, Alianza Editorial, Madrid, 2001, el interés de la mayoría no siempre puede imponerse a la minoría. El interés colectivo (que puede ser el interés de clase), debe respetar determinados derechos de los ciudadanos. También este autor recuerda la existencia de intereses siniestros (en terminología de Bentham), que son aquellos que en mayor o menor medida están en conflicto con el bien general de la comunidad.

14 Véanse, por todos, Muñoz Machado, S., "Las concepciones del Derecho administrativo y la idea de participación en la Administración”, RAP, n. ${ }^{84}$, septiembre-diciembre 1977. Charles-Albert Morand (ed.), L'Etat propulsif. Contribution à l'étude des instruments d'action de L'Etat,Publisud, Paris, 1991. Moor, P., Droit admnistratif, vol. II Les actes administratifs et leur contrôle, Staempfi Editions, Berne, 2002, p. 48 y siguientes.Flückiger, A., “L'essor des actes étatiques incitateurs: le glas de la loi?”, Législation et Evaluation, 2001/1. De este mismo autor "Régulation, dérégulation, autorégulation: l'emergence des actes etatiques non obligatoires", Révue de droit suisse, 2/2004. 
rre en las monarquías moderadas y en los gobiernos bien estructurados- el bien de la sociedad requiere que varios sean los asuntos que se dejen a la discreción de quienes ostenten el poder ejecutivo, pues como los legisladores no pueden prever y procurar mediante leyes todo lo que pueda serle útil a la comunidad, el ejecutor de las leyes, al tener el poder en sus manos, tiene, por ley común de la naturaleza, el derecho de hacer uso de dicho poder para el bien de la sociedad (...) Hay muchas cosas que en modo alguno pueden ser previstas por la ley; y ésas son las que han de dejarse necesariamente a la discreción de quien tenga el poder ejecutivo en sus manos, para que él decida según lo que el bien y el beneficio del pueblo requieran". El mismo autor añade que "este poder de actuar a discreción para el bien público, sin hacerlo conforme a lo prescrito por la ley, y aún contra ella en ciertos casos, es lo que se llama prerrogativa. Pues como en algunos gobiernos el poder legislativo no está siempre en activo, y suele ser también muy numeroso y, por ende, muy lento en despachar sus decisiones al ejecutivo; $y$ como es imposible prever y abarcar con las leyes todas las posibles eventualidades y necesidades que puedan afectar al pueblo; y como es asimismo imposible hacer leyes que no produzcan daño cuando son aplicadas con rigor inflexible en todas las ocasiones y a todas las personas que estén en su camino, hay un margen que es dejado al poder ejecutivo para que éste tome decisiones que la ley no ha prescrito"'s.

Constant decía expresamente que "es imposible, repito, reglamentarlo todo, ponerlo todo por escrito, y hacer de la vida y de las relaciones entre los hombres un acta procesal redactada de antemano, en la que sólo los nombres estén en blanco, y que ahorre a las generaciones futuras cualquier reflexión, cualquier idea, cualquier recurso a la inteligencia". "Haga lo que se haga", añadía, "queda siempre en los asuntos humanos cierta dosis de discrecionalidad"16.

El Legislador, que ya sabemos que por la intervención y el funcionamiento de los partidos políticos puede llegar a confundirse con el Gobierno de turno si existe una mayoría suficiente en el Congreso, insistimos, muchas veces remite al propio Gobierno o a la Administración la concreción de los intereses generales ${ }^{17}$. Reconoce a ésta, cuando menos, un margen de libertad para decidir que sea de interés general en un momento dado ${ }^{18}$. A la reducción de la discrecionalidad en las leyes se ha referido,

15 Locke, J., The Second Treatise..., cit., p 164-171.

16 Constant añade: “Ahora bien, si, se haga lo que se haga, queda siempre en los asuntos humanos cierta dosis de discrecionalidad, me pregunto: ¿no es mejor que el ejercicio del poder que esa parte discrecional exige se confíe a personas que no lo ejerzan más que en una sola ocasión, que no se corrompan ni se cieguen por el hábito de la autoridad y que estén interesadas a la vez en la libertad y en el orden, que ponerlo en manos de personas que tienen como interés permamente sus prerrogativas particulares?".

17 Por todos Parada Vazquez, R., Derecho administrativo I, Parte General, decimoquinta edición, Marcial Pons, Madrid, 2004, p. 18.

18 Cerulli Irelli, V., Lineamenti del diritto amministrativo, G. Giappichelli Editore, Torino, 2010, p. 279 y siguientes, recuerda que Giannini se refería al "interés primario" establecido en la norma, que justifica la atribución y el ejercicio de una determinada potestad. Los intereses secundarios son los que aparecen en la realidad, en la concreta situación de hecho en la que incidirá el ejercicio de la potestad. Insiste, lógica62 mente, en la necesidad de identificar el concreto interés que persigue la acción pública y en la razodida que se adopte. Defiende que la motivación es siempre relevante jurídicamente. 
entre otros, el Profesor Tomás Ramón Fernández, que ha subrayado la importancia de los límites que la Constitución y los principios constitucionales imponen al Legislador ${ }^{19}$.

\subsection{La discrecionalidad administrativa o la definición del interés general por la propia Administración}

La discrecionalidad, tal y como decía la Ley de la jurisdicción contencioso-administrativa de 1956, aparece cuando el ordenamiento jurídico atribuye a algún órgano competencia para apreciar, en un momento dado, lo que sea de interés público. La discrecionalidad administrativa, de acuerdo con el Profesor Muñoz Machado, es la libertad de la Administración para definir el interés general ${ }^{20}$.

Muchos autores se han referido a la escasez de leyes por contraposición al abundante número de reglamentos aprobados por la Administración ${ }^{21}$. Aqui únicamente destacaremos que el ejercicio de la potestad reglamentaria, que en gran parte tiene carácter discrecional, puede concretar algo más el interés que ha de perseguir la actuación administrativa, reduciendo así el margen de libertad en la decisión del caso concreto $^{22}$. No se puede, sin embargo, como decíamos antes, reglamentar todo. Las normas, por ejemplo cuando utilizan conceptos jurídicos indeterminados, remiten al análisis del caso concreto que realiza la Administración, a su apreciación, si así se prefiere. En más ocasiones de las que puede creer un lego en Derecho es la propia Administración la que, lógicamente ajustándose a lo que establezcan las leyes, concreta los intereses generales a los que sirve en las normas que aprueba o en las decisiones que adopta.

Ya hace muchos años, por lo demás, que viene hablándose del tránsito de una Administración que impone unilateralmente sus decisiones, que conserva rasgos cla-

19 Fernández Rodríguez, T. R., "Sobre los límites constitucionales del poder discrecional”, RAP, 187, enero-abril 2012, p. 148 y siguientes. Sobre las convalidaciones legislativas en Francia puede verse, entre otras, la resolución del Consejo constitucional francés de 28 de febrero de 2012, n. ${ }^{\circ}$ 2011-224-QPC, sobre la convalidación por el Parlamento de una licencia para construir un museo en el Bois de Boulogne, que había sido anulada. Considera su Tribunal Constitucional que reforzar el atractivo turístico de París constituye un motivo de interés general que justifica la convalidación. Responde a un objetivo de interés general suficiente, el legislador ha motivado su decisión, y delimitado la zona ("la portée de la validation est strictement définie"). La disposición recurrida, además, no es contraria a ningún derecho o libertad constitucional.

20 Muñoz Machado, S., Tratado de Derecho administrativo..., cit., p. 530 y siguientes.

21 Sobre la crisis de la ley valga por todos Mathieu, B., La loi, Dalloz, Paris, 2004, 2. edición.

22 Baño León, J. M. ${ }^{a}$, Los límites constitucionales de la potestad reglamentaria (Remisión normativa y reglamento independiente en la Constitución de 1978), Civitas-Servicio de Publicaciones Facultad de Derecho de la Universidad Complutense, 1991. El mismo autor, Derecho urbanístico común, lustel, 2009, p. 116, señala que las “leyes no son el instrumento más importante de la ordenación” urbanística. "A medida que se intensificara la densidad normativa de la ley, disminuiría en la misma intensidad la competencia local para establecer la política territorial". Moor, P., Droit admnistratif, vol. II Les actes administratifs et leur contrôle, Staempfi Editions, Berne, 2002, pp. 443-444. 
ramente autoritarios, a una Administración que, además de lo anterior, pacta, negocia o firma convenios con los destinatarios de las concretas políticas públicas. La actividad que desarrolla la Administración para satisfacer los fines de interés general, que puede acabar definiendo ella misma tras un pacto con los privados, tiene carácter objetivo. Debe hacerse con sometimiento pleno a la Ley y al Derecho y es fiscalizable por los Tribunales. La Administración debe cumplir con ese principio de actuación. Y los Juzgados y Tribunales, lógicamente, están encargados de sancionar su incumplimiento. La superación del principio de legalidad y su conversión, en algunas materias y en determinados casos, en el principio de juridicidad, como vemos seguidamente, amplía las posibilidades de control por parte de jueces y magistrados ${ }^{23}$.

\section{EL CONTROL POR LOS TRIBUNALES DEL EJERCICIO DEL PODER EJECUTIVO}

El control por los Tribunales del desarrollo de las funciones ejecutivas o de gobierno es otro de los asuntos que, desde hace siglos, ocupa muy especialmente a los estudiosos del Derecho público. Durante muchas centurias, lógicamente, la actividad política, el ejercicio de las prerrogativas por el Gobierno o por su Administracion, estuvo en gran parte exenta del control por los Tribunales. La fiscalización de la actuación del Poder Ejecutivo, pese a que destacados nombres hayan denunciado que sufre curiosos altibajos en algunas materias y en determinadas épocas ${ }^{24}$, ha ido ampliándose con el paso del tiempo ${ }^{25}$. El artículo 106 de la Constitución, en

23 Morand, Charles.-.Albert, “La légalité de la légalité”, en Figures de la légalité, Publisud, Paris, 1992, p. 187 y siguientes.

24 Bocanegra Sierra, R., Huergo Lora, A., “Un paso atrás en el control judicial de la discrecionalidad: su confusión con los conceptos jurídicos indeterminados y la dispensa del deber de motivar", REDA, 111, julio-septiembre 2011, p. 405 y siguientes, analizan con cierto detalle las sentencias recaídas en relación con algunos nombramientos realizados por el Consejo General del Poder Judicial. No se trata, pues, del Poder Ejecutivo sino del Poder Judicial. Puede verse sobre estas cuestiones la STS de 7 de febrero de 2011, recurso 343/2009, ponente Nicolás Maurandi Guillén. Se admite que la motivación en los nombramientos del CGPJ es necesaria pero se plantea el debate sobre si para los cargos directivos "la libertad de apreciación y opción del Consejo opera en su nivel máximo", si "el amplísimo margen de apreciación que debe serle reconocido en lo tocante a decidir cuál de los proyectos de gobierno aportados por los candidatos encarna mejor la opción de política judicial del Consejo y, también, cuál de esos candidatos, una vez demostrado que ha superado un razonable umbral de profesionalidad, es el que le parece más idóneo para ejecutar dicha política en el concreto territorio para el que sea nombrado". Existen votos particulares más que interesantes. En esta materia resultan fundamentales, entre otras, las SSTS de 27 de noviembre de 2007 (recurso 407/2006), y 23 de noviembre de 2009 (recurso 372/2008).

25 Locke, J., The Second Treatise..., cit., p 170, sostenía, todavía a finales del s. XVII, que no cabía control judicial del ejercicio por el Gobierno de sus prerrogativas. "La vieja pregunta acerca de este asunto de la prerrogativa vuelve a plantearse: ¿Quién podrá juzgar si se ha hecho recto uso de este poder? Y respondo: No puede haber juez sobre la tierra entre un poder ejecutivo en activo y un poder legislativo que depende de aquél para reunirse; y tampoco puede haberlo entre el poder legislativo y el pueblo, caso de que el ejecutivo o el legislativo, con el poder ya en sus manos, se propongan esclavizarlo o destruirlo". Duguit, L., Les transformations..., cit., p. 147 y siguientes, describe la evolución en Francia del control de legalidad de la actuación administrativa, recuerda que la interpretación de la división de poderes hacía que el control quedase reservado a la propia Administración. En la p. 160 y siguientes recuerda que durante 
nuestros días, dice que los Tribunales controlan la potestad reglamentaria, la legalidad de la actuación administrativa y el sometimiento de la Administración a los fines que la justifican ${ }^{26}$. Toda la actuación administrativa, también la discrecional, está sometida al control que ejercen los órganos del orden jurisdiccional contencioso-administrativo. El grado de libertad o discrecionalidad, y la profundidad del control jurisdiccional, varía, lógicamente, según el poder administrativo o materia de que se trate. Distinguimos en las siguientes líneas entre el control del ejercicio de la potestad reglamentaria y el control de los actos discrecionales de la Administración. Las técnicas son bien conocidas por cualquier especialista, e incluyen el control de las cuestiones regladas (procedimiento, competencia...) ${ }^{27}$, o la prohibición de la desviación de poder. Jueces y magistrados pueden fiscalizar si se ha perseguido un fin, público o privado, distinto del establecido en la norma (artículo 70.2 de la Ley $29 / 1998)^{28}$.

muchos años se entendió en Francia que la Administración no estaba vinculada por sus actos unilaterales, "on y voyait un ordre de la puissance commandante, ordre qu'elle pouvait par conséquent retirer comme bon lui semblait”. Apunta el trabajo de Jèze, publicado en la Revue du droit public, 1911, p. 61, sobre la jurisprudencia recaída entre 1910 y 1911, que negaba esta posiblidad a la Administración si el acto había sido legalmente adoptado (p. 161). En la p. 197 y siguientes, recuerda que las normas reglamentarias de desarrollo, durante mucho tiempo, no fueron susceptibles de recurso. Apunta la vinculación que se hizo entre algunos actos políticos y la razón de Estado, y señala la feliz superación de estas cuestiones, que es una de las pincipales transformaciones del Derecho púbico que pretende describir (p. 199-200). Recuerda que "c'est une tendance naturelle aux hommes qui occupent le pouvoir de vouloir soustraire leurs actes au controle des tribunaux" (p. 204). La evolución de la justicia administrativa o contencioso-administrativa, de las relaciones entre la Administración y la Justicia puede verse en muchas partes. Por todos Tocqueville, A., L'ancien régime et la Révolution (1856). Cito aquí por la edición de J.-P. Mayer, Éditions Gallimard, 1967, p. 122 y siguientes, que constituyen el contenido del capítulo IV del Libro II, "Que la justice administrative et la garantie des fonctionnaires sont des institutions de l'ancien régime”. Muñoz Machado, S., Tratado de Derecho administrativo..., cit., p. 263 y siguientes.

26 Leguina Villa, J., “Artículo 106.1 El control judicial de la Administración pública”, en Comentarios a la Constitución española, p. 1724 y siguientes, menciona las SSTC 34/1995 y 103/1996, que reconocieron que el control judicial es "la auténtica cláusula regia del Estado de Derecho". Considera que, "en cierto modo, el art. 106.1 es una prolongación del art. 24.1" (p. 1725). En la p. 1726 recuerda que el TC (Sentencias 136/1995 y 294/1994), ha afirmado que no existen comportamientos de la Administración inmunes al control judicial. Nieto, A., El desgobierno..., cit., p. 306, como muchos otros, señala que "los tribunales son el contrapeso más importante del Poder, el freno de la arbitrariedad”, aunque el mismo Profesor ha publicado sus ideas sobre la arbitrariedad de los jueces. Véase, por ejemplo, NIETO, A., El arbitrio judicial, Ariel, Barcelona, 2000.

27 El procedimiento administrativo, al margen de una garantía para los ciudadanos, pretende conseguir el acierto y la objetividad en las decisiones que adopte la Administración. El procedimiento administrativo, de acuerdo entre muchos otros con el Profesor Esteve Pardo, J., Lecciones de Derecho administrativo, Marcial Pons, Madrid, 2011, p. 175, "se orienta a sujetar la actividad administrativa a criterios de racionalidad y objetividad".

28 Duguit, L., Les transformations..., cit., p. 157, insiste en que la Administración siempre persigue el funcionamiento legal de un servicio público, y que "si la volonté de l'agent est déterminée par un but étranger au service public, il y a usurpation de pouvoir; si elle est déterminée par un but de service public, mais par un but que l'agent n'a pas compétence pour poursuivre, il y a détournement de pouvoir. Usurpation de pouvoir, détournement de pouvoir, deux notions juridiques qui se rattachent directement à I 'idée de but". Muñoz Machado, S., Tratado de Derecho administrativo..., cit., p. 579, recoge algunos casos en que el TS ha anulado la actuación administrativa por incurrir en desviación de poder, en el planeamiento urbanístico, en la tramitación de expedientes administrativos, pero también en la selección de personal y en el cese de funcionarios. El Código europeo de buena conducta administrativa se refiere al abuso de poder 
Los Tribunales pueden controlar si la potestad administrativa fue regularmente atribuida, o si se da el supuesto de hecho que legitima el ejercicio de la misma ${ }^{29}$. Pueden analizar, en fin, si la norma reglamentaria o la actuación administrativa respeta el Ordenamiento jurídico, con todos sus principios jurídicos.

\subsection{El control judicial de la potestad reglamentaria}

Una vez reconocida la potestad reglamentaria a la Administración durante largo tiempo se sostuvo que su ejercicio tenía carácter político, que pertenecía a la función de gobierno y que no resultaba fiscalizable por los Tribunales. Mucho se ha avanzado estos últimos cincuenta años en nuestro país, desde luego, en el control del poder normativo de la Administración ${ }^{30}$.

Es claro, no obstante esos avances, que el grado de libertad de la Administración varía según el tipo de norma reglamentaria de que se trate. Así, por ejemplo, se ha reconocido un mayor margen de decisión a la Administración en los Reglamentos que

(artículo 7), y el Tratado de Funcionamiento de la Unión Europea ha previsto que frente a una desviación de poder de la Administración de la Unión Europea pueda interponerse un recurso de anulación (artículos 263-264).

29 Asunto que remite, por supuesto, al debate sobre la plenitud de la prueba en el contenciosoadministrativo y a la superación de su carácter revisor. Muñoz Machado, S., Tratado de Derecho administrativo..., cit., p. 566 y siguientes.

30 La primera vez que el Tribunal Supremo sostuvo que los principios generales del Derecho constituían un límite a la potestad reglamentaria fue, según parece, en una Sentencia de 20 de febrero de 1959, que aplicó el principio de proporcionalidad. Véase García de Enterría, E., "La interdicción de la arbitrariedad en la potestad reglamentaria", RAP, n. ${ }^{\circ}$ 30, septiembre-diciembre 1959. También analiza el citado Profesor la STS de 6 de julio de 1959. En esta resolución se aplicó la técnica del control de los hechos determinantes (p. 149), y el principio de igualdad. Resaltó el Profesor García de Enterría el avance que suponían estas sentencias pero advirtió, del mismo modo, "que este control tiene que ser hecho desde criterios objetivos de derecho, que respete íntegra la responsabilidad de los juicios políticos que toda elaboración normativa implica necesariamente, juicios en los cuales el Tribunal no tiene competencia para penetrar" (p. 159). Resulta clásica en el control de los hechos determinantes la cita del arrêt Gómel, de 4 de abril de 1914. Dejamos al margen, entre otras cosas porque se trata de normas con rango legal aprobadas por el Gobierno, las SSTC sobre la extraordinaria y urgente necesidad que exige el artículo 86.1 CE para aprobar Decretos leyes. Puede verse, entre otras, la STC 189/2005, de 7 de julio, donde se insiste en la doctrina del Alto Tribunal de "reconocer el peso que en la apreciación de la extraordinaria y urgente necesidad ha concederse al juicio puramente político de los órganos a los que incumbe la dirección del Estado", aunque recuerda que es necesario que se expliciten dichas razones de extraordinaria y urgente necesidad, y que el Tribunal puede controlar si la urgencia se corresponde con las medidas que se adoptan. Destaca, no obstante, que el juicio político está vedado al Tribunal Constitucional, "es un control externo, en el sentido que debe verificar, pero no sustituir, el juicio político o de oportunidad que corresponde al Gobierno y al Congreso de los Diputados en el ejercicio de la función de control parlamentario". La STC 137/2011, de 14 de septiembre, anula una artículo de un Real Decreto-ley por falta de justificación. Esta Sentencia tiene voto particular en contra de los magistrados Javier Delgado Barrio y Manuel Aragón Reyes. Más reciente es la STC 1/2012, de 13 de enero,que anula un precepto de un decreto-ley por vulnerar las competencias autonómicas. La distribución de competencias, lógicamente, es un límite a los decretos-leyes. El empleo de este tipo de normas es abundante estos últimos tiempos. Cuando se redactan estas líneas el Gobierno ha aprobado en 5 meses 66 nistrativo de los Reales Decretos-legislativos. 
son, a su vez, manifestación de su poder de autoorganización ${ }^{31}$, o se refieren al empleo público32.

La Administración, en la práctica, goza de amplia libertad en la aprobación de normas de marcado carácter técnico (que muchas veces, curiosamente, se elaboran teniendo en cuenta la información facilitada por los sujetos privados). Particu-

31 A la libertad en el ejercicio de la potestad de autoorganización nos referimos en Ureña Salcedo, J. A, “Las novedades introducidas en la organización administrativa estatal por la Ley Orgánica 3/2007”, en Comentarios a la Ley Orgánica 3/2007, de 22 de marzo, para la lgualdad efectiva de mujeres y hombres; Tomás Sala Franco, María Amparo Ballester Pastor, José María Baño León, José Miguel Embid Irujo, José María Goerlich Peset (coordinadores), La Ley-Wolters Kluwer España SA, Las Rozas, 2008. Puede verse la STS de 31 de octubre de 2006, recurso 68/2005, que dice que "si la potestad reglamentaria es en si misma, discrecional, con sólo los límites que le impone la ley habilitante y el resto del ordenamiento jurídico, en mayor medida esa discrecionalidad se acrecienta cuando en el ejercicio de dicha potestad se están desarrollando funciones organizatorias. En estos casos, aparte de los límites anteriores, sólo en supuestos de arbitrariedad o irracionalidad será posible ejercer una función de control de los poderes de la Administración". La STS de 27 de noviembre de 2006, recurso 53/2005, Ponente Baena del Alcázar, recaída sobre una norma de organización administrativa, plantea un tema dogmáticamente interesante (como es la inclusión en una norma reglamentaria de un acto administrativo). Recuérdese que la disposición adicional única del Real Decreto 2397/2004, de 30 de diciembre, ordenaba el traslado de la sede de la Comisión del Mercado de Telecomunicaciones desde Madrid a Barcelona. Entiende el TS que se trata de "una norma de organización que se dicta en el ejercicio de una potestad discrecional del Gobierno. Pero eso no significa que esté exenta de la necesaria sumisión al ordenamiento jurídico, como sucede también con ciertos actos del Gobierno de contenido político". Existen elementos reglados como "la sumisión a las normas de procedimiento" que son fiscalizables. Entiende que el dictamen del Consejo de Estado era innecesario, pues "no estamos ante un reglamento que establezca con carácter general derechos y obligaciones de los ciudadanos y de las Administraciones públicas". Considera, no obstante, que la memoria justificativa, como la económica, es insuficiente, pues "sólo emitió informe la Secretaría General Técnica del Ministerio de Administraciones Públicas". Añade que "No se expresa en cambio ningún razonamiento que determine la necesidad y oportunidad de la decisión". Considera que el cumplimiento del artículo 24 de la Ley del Gobierno "ha sido meramente formal, sin que se logre la finalidad querida por el legislador de que en efecto se patentice la necesidad y oportunidad del reglamento como garantía del acierto en la decisión, y se valoren los costes económicos que son consecuencia de la ejecución de la medida". Existe un voto particular de varios magistrados que discrepan del parecer de la mayoría de la Sala al considerar que se trata de un acto administrativo, "un acto singular, expresión de la dirección política”, al que no resulta de aplicación el artículo 24 Ley del Gobierno. "La forma no determina la naturaleza de lo acordado ni atribuye carácter normativo a un acto que agota sus efectos de una sola vez". Añaden, además, que "sostener que no hay justificación es negar lo evidente". Sobre un "informe" que contiene "decisiones administrativas" véase la STS de 4 de mayo de 2010, recurso de casación 3856/2007, ponente Excmo. Sr. D. Eduardo Espin Templado, en relación con la inspección de las Cajas de Ahorros vascas por el Gobierno autonómico.

32 En los últimos años, sin embargo, y es importante hacerlo notar, se han dictado numerosas sentencias por el Tribunal Supremo que han anulado las modificaciones de las relaciones de puestos de trabajo al entender que no estaba suficientemente motivada la elección de la libre designación para cubrir determinados puestos. El TS ha insistido en el "carácter excepcional que la Ley asigna a este sistema de libre designación y en la necesidad de que cuando se considere necesario acudir a él se haga, también excepcionalmente, y justificando, caso por caso, por qué debe utilizarse". Los requisitos de edad exigidos en algunas convocatorias también han sido anuladas por falta de justificación razonable. Véase la STS 21 de marzo de 2011, recurso 184/2008, que anula el requisito de la edad (30 años) para acceder a la Escala Ejecutiva del Cuerpo Nacional de Policía. La STS 25 de enero de 2012, recurso de casación 560/2011, ponente Vicente Conde Martín de Hijas, declara no haber lugar al recurso de casación interpuesto frente a la Sentencia que anuló el Decreto 277/2007, de 6 de noviembre, por el que se modificaba la relación de puestos de trabajo de la Administración General de la Junta de Andalucía. Considera el Tribunal que no es suficiente con fórmulas genéricas o estereotipadas. 
larmente interesante, aunque no podamos detenernos, resulta el ejercicio de la potestad reglamentaria por las Administraciones independientes o por las Agencias reguladoras ${ }^{33}$.

En los Reglamentos que inciden en la propiedad privada, y muy significativamente en la redacción de planes y otras normas urbanísticas, la libertad de la Administración ha sido notable. La discrecionalidad administrativa en el planeamiento municipal, en el diseño de la ciudad, ha sido limitada en parte con las directrices legales y con la aprobación de planes supramunicipales jeráquicamente superiores ${ }^{34}$. Cada vez es mayor el número de sentencias que, por ejemplo, exigen a la Administración una motivación especialmente reforzada 35 .

33 Esteve Pardo, J., "La revisión judicial de las decisiones de las autoridades reguladoras. Jurisprudencia del Tribunal Supremo y la Audiencia Nacional”, en Derecho de la regulación I. Fundamentos e instituciones de la regulación, Muñoz Machado, S, Esteve Pardo, J., (directores), lustel, Madrid, 2009, en particular a partir de la página 900.

34 Baño león, Derecho urbanístico..., p. 118 y siguientes, se refiere a los límites legales a la discrecionalidad del planificador. En las páginas 126-127 destaca la importancia de la motivación y sostiene que es posible la "discrecionalidad cero". El Tribunal Supremo, en Sentencia de 29 de abril de 2011, recurso de casación 1755/2007, sobre la revisión de un PGOU, acepta que se ha producido un "ejercicio abusivo de la jurisdicción". La Sentencia que resulta casada "sustituye a la Administración al decidir adoptando determinaciones que no tienen una alternativa única y que, por tanto, siguen correspondiendo constitucionalmente en exclusiva a la Administración". Recuerda que "a diferencia de lo que acontece en el control de legalidad sobre potestades regladas (...) en el control de la denominada discrecionalidad técnica del planificador urbanístico el Derecho no siempre proporciona al Tribunal todos los datos necesarios para sustituir el acto administrativo por el jurisdiccional, por lo que, en dicha medida, la actividad discrecional no resulta enteramente enjuiciable jurisdiccionalmente". La STS 22 de septiembre de 2011, recurso de casación 277/2008, ponente Eduardo Calvo Rojas, considera arbitraria la calificación de unos terrenos en un PGOU como "sistema de espacio libre de conexión territorial" sin precisar su carácter público o privado, y anula la misma. No accede a la pretensión de que sean calificados como suelo agrícola, pues corresponde a la "Administración urbanística competente sustituir la decisión anulada por otra, de entre las distintas alternativas posibles".

35 La STS de 13 de junio de 2011, recurso de casación 4045/2009, ponente Pilar Teso Gamella, declara no haber lugar al recurso de casación interpuesto frente a una sentencia que había estimado el recurso frente a la revisión del PGOU de Sevilla, en lo relativo a la ubicación de la Universidad en una antigua zona verde. Recuerda la discrecionalidad del planificador "para que adopte la decisión que resulte acorde con el interés general", reconoce que "la potestad de planeamiento incluye la de su reforma o sustitución, realizando los ajustes necesarios al ritmo que marcan las exigencias cambiantes del interés público", pero remarca que "esta amplia discrecionalidad se torna más estrecha cuando se trata de actuar sobre zonas verdes. $Y$ decimos que se reduce el ius variandi porque las zonas verdes siempre han tenido un régimen jurídico propio y peculiar, que introducía una serie de garantías tendentes al mantenimiento e intangibilidad de estas zonas, e impidiendo que fueran borradas del dibujo urbanístico de ciudad, sin la concurrencia de poderosas razones de interés general". Considera que el cambio de calificación de los terrenos de un parque a equipamiento educativo (la biblioteca de la Universidad) no ha sido debidamente justificada. Y cuando "se trata de ubicar una edificación, aunque sea de las características de la ahora proyectada, sobre una zona verde, ha de intensificarse tal exigencia de motivación, más allá de la que habitualmente se precisa. Esta es precisamente otra peculiariedad del régimen jurídico de la zona verde, que su desaparición, en todo o en parte, sitúa el umbral de motivación en un nivel superior al exigible ordinariamente". La libertad del planificador "no desaparece ante las zonas verdes, pero si se reduce considerablemente. Esa libertad queda limitada únicamente a los casos en que se advierta una potente presencia de los intereses generales que demanden la reducción de la zona verde, que no es el caso". Considera que en el caso se enfrentan "dos intereses igualmente públicos y legítimos. El de la comunidad universitaria y el de todos los ciudadanos ve- 
La Administración ha gozado de gran libertad en la aprobación de los reglamentos que incidían en la libertad de empresa o, más ampliamente, en el desarrollo de actividades por los privados. Exactamente lo contrario que ha ocurrido con los reglamentos sancionadores, donde lógicamente ha sido menor la libertad de la Administración, pues en teoría únicamente puede completar o desarrollar los tipos legales. Cabe la colaboración del reglamento siempre que la ley fije los elementos esenciales de las infracciones administrativas ${ }^{36}$. El principio de legalidad tiene un contenido garantizador especialmente relevante en materia sancionadora. La Administración, al menos sobre el papel, goza aquí de menor libertad.

\subsection{El control por los Tribunales de los actos de la Administración}

En las siguientes líneas nos centramos en el control judicial de las decisiones, resoluciones u actos de la Administración. No entramos en mayor detalle, ni nos detenemos en asuntos tan interesantes como el control del cumplimiento de determinados convenios, o la fiscalización jurisdiccional de la actividad informal y material de la Administración. Nos basta con recordar que el artículo 106 CE se refiere al control por los Tribunales de toda la actuación administrativa. El ámbito decisorio de la Administración exento del control por los Tribunales, al menos sobre el papel, también se ha reducido notablemente en los últimos años. A los actos políticos, de autoridad, de imperium o de pura administración, se han dedicado numerosas e imprescindibles páginas ${ }^{37}$.

cinos de esa ciudad" (aunque se tratase de una comunidad de propietarios, no defendía sus vistas al parque, sino que ejercitaban una acción pública, y en el fondo se esgrimía un interés por la defensa de la zona verde).

36 Otra cosa es que la complejidad de los ordenamientos obligue a repensar si el principio de legalidad del s. XVIII-XIX puede mantenerse en el s. XXI con la misma interpretación. Las brechas son numerosas. Sobre la necesidad de completar los tipos legales, o las remisiones en blanco de la ley al reglamento en ordenamientos tan complejos, puede verse la STC 60/2000, de 2 de marzo, que cuenta con un voto particular del magistrado Fernando Garrido Falla. Sobre la anulación de una sanción por no tener cobertura legal sino reglamentaria puede verse la STC 135/2010, y la STS de 4 de noviembre de 2011, recurso de casación 6062/2010, que anula una Orden del Ministerio de Medio Ambiente por no respetar el principio de legalidad en materia sancionadora. Sobre el principio de legalidad sancionadora y la obligación de incorporar las mejores técnicas disponibles puede verse la STC 8/2012, de 18 de enero. Nieto, A., Derecho administrativo sancionador, Tecnos, Madrid, 1994, 2. edición, p. 291, ya hace años que apuntó que el principio de legalidad y tipicidad sufría un deterioro general.

37 Sobre la distinción entre Gobierno y Administración, como es bien sabido, se ha escrito mucho desde hace algunos siglos. Debate clásico, en el que no podemos entrar ahora, que va de la mano de la discusión, intensa también en nuestro país, del control por los Tribunales de los actos políticos. Puede verse, entre muchos otros, ALLI ARANGUREN, J.-C., La construcción del concepto de Derecho administrativo español, Thomson-Civitas, Cizur Menor (Navarra), 2006. Sobre los actos de gobierno o actos políticos a principios del s. XX en Francia puede verse, por ejemplo, Duguit, L., Les transformations..., cit., p. 147 y siguientes, sostiene que el deseo de limitar el control de la actividad que desarrolla la Administración es el que inspiró la distinción entre actos de autoridad y actos de gestión. Recuerda el Profesor francés que el 29 de febrero de 1908, caso Feutry, se había dictado una fundamental resolución del Tribunal de Conflictos que negaba esta distinción entre actos de autoridad y actos de gestión (p. 155). En la p. 197 y siguientes, recuerda que el control de la Administración mediante el recurso por exceso de poder es admisible, incluso, cuando el acto de gobierno se inspira en razones políticas (p. 205). El acto discrecional, añade, puede ser recurrido por incompetencia o vicio de forma. La discusión sobre el control de estos actos de libre apreciación, utilizando la denominación alemana, reconoce que es grande todavía en 1913, pero a su juicio “le conseil d’État est toujours compétent pour apprécier le but qui a déterminé l'acte et il en prononce l'annulation s'il estime que 
En nuestros días, ya lo hemos dicho, los Tribunales pueden utilizar todas las técnicas de control de la discrecionalidad administrativa. Pueden fiscalizar si la decisión administrativa se ajusta, por ejemplo, a los principios generales del Derecho, algunos de ellos con rango constitucional, como la interdicción de la arbitrariedad (artículo 9.3 $\mathrm{CE}$ ), que exige que la decisión sea razonable y esté motivada ${ }^{38}$. Las sentencias que recuerdan la necesidad de motivación suficiente, y en ocasiones el deber de motivación especialmente reforzado, son numerosas ${ }^{39}$.

I'administateur, tout en étant resté dans les limites formelles de sa compétence, a poursuivi un but autre que celui que la loi avait en vue en lui donnant cette compétence” (p. 207). Describe la desviación de poder, y sostiene que "on comprend maintenant comment il n'y a plus, comment il ne peut plus y avoir d'actes discrétionaires ou de pure administration. Quelque étendue que soit la compétence d'un administrateur, l'administré a toujours le pouvoir de lui demander compte des motifs qui l'ont déterminé". Muñoz Machado, S., Tratado de Derecho administrativo..., cit., p. 598 y siguientes. En la página 604 recuerda que tanto el TS como el TC han admitido que existe actividad política del Gobierno no sujeta a control por los Tribunales, aunque "la exclusión total de control es contraria al principio de legalidad y al de tutela judicial efectiva". Recuerda los casos de nombramiento del Fiscal General del Estado, de la desclasificación de documentos secretos, y la negativa a controlar la iniciativa legislativa ejercida por el Gobierno. Vid sobre secretos oficiales la STS de 4 de abril de 1997, recurso 602/1996. Sobre el carácter político de los acuerdos del Consejo de Ministros de envío de ayuda humanitaria puede verse el Auto del TS de 8 de enero de 2004, recurso 122/2003, Ponente Baena del Alcázar. Considera el citado Profesor, en fin, que también los actos de naturaleza política son controlables "en la medida en que la legalidad los somete al cumplimiento de requisitos o criterios que pueden ser apreciados en sede judicial”. "El método de control de estos actos de componente básicamente político es sustancialmente el mismo que se emplea para el control de los actos discrecionales”. Sobre los secretos de Estado, Constant, B., Principes de politique...,cit., p. 87, sostiene que el hecho de que los tribunales no pudiesen conocer de los denominados "secretos de estado" era "un resto del sistema que admitía que la seguridad del Estado podía exigir actuaciones arbitrarias". Añade que "creo que la seguridad pública se ve realmente comprometida cuando los ciudadanos ven en la autoridad un peligro en lugar de una salvaguardia. Creo que el auténtico enemigo de la seguridad pública son los actos arbitrarios; que las tinieblas en las que se esconde la arbitrariedad no hacen más que agravar esos peligros; que sólo hay seguridad pública con la justicia, que sólo hay justicia con las leyes, que sólo hay leyes con procedimientos formales. Creo que la libertad de un solo ciudadano interesa lo suficiente al cuerpo social como para que sus jueces naturales deban conocer las causas de cualquier rigor ejercido contra él. Creo que ése es el objetivo principal, el fin sagrado de cualquier institución política, y que, dado que ninguna Constitución puede legitimarse de otra manera, será inútil que busque de otra forma la fuerza y la permanencia segura".

38 Nieto, A., "La Administración sirve con objetividad...", cit., p. 2240, cita una STS de 2 de junio de 1967, que anulaba una resolución administrativa por falta de justificación adecuada. Se sostenía que la discrecionalidad no podía confundirse con el libre arbitrio. Puede verse el trabajo del Profesor Fernández Rodríguez, T.-R., "Arbitrariedad y discrecionalidad en la doctrina jurisprudencial constitucional y administrativa", Revista General de Derecho Administrativo, n. ${ }^{\circ}$, diciembre de 2003, p.4, que entiende que la distinción entre discrecionalidad y arbitrariedad en la jurisprudencia también puede verse en la STS de 13 de julio de 1984, recaída para resolver el problema de la delimitación del ámbito territorial de la denominación de origen Jerez-Xerez-Sherry.

39 Sánchez Morón, M., “Artículo 103 CE”, cit., p. 1695, recoge un buen número de Sentencias del Tribunal Constitucional sobre los principios de mérito y capacidad, donde se ha hecho referencia a la necesidad de evitar las reservas ad personam, las prohibiciones de discriminación por razón de residencia o del lugar donde se adquirió la titulación requerida, etc. En la STS de 6 de julio de 2011, recurso de casación 735/2008, ponente Nicolás Maurandi Guillén, se reconoce el derecho del recurrente a la adjudicación del contrato de sumistro. La Administración declaró desierto el concurso porque a su juicio ninguna oferta cumplía los requisitos exigidos en el Pliego de prescripciones técnicas. Considera el Tribunal que "en el caso enjuiciado no se ha justificado, en términos técnicos que puedan ser considerados aceptables, que la oferta de la recurrente no cumpliera con dichas exigencias". No hubo una "motivación aceptable" por parte de la Administración. Entiende que "tratándose de decisiones administrativas que comportan la necesidad de una valoración técnica, esta valoración ha de estar debidamente justificada para que la decisión administrativa pueda ser considerada debidamente motivada". 
Bien conocidas son las resoluciones judiciales que, recaídas en distintos ámbitos, anulan decisiones de la Administración por ser simples formularios ${ }^{40}$. A la motivación por remisión a documentos que obran en el expediente se han referido, y también resulta conocido, numerosas resoluciones judiciales.

Existen ocasiones, como ha recordado varias veces el TC, en que la Administración decide fundándose en juicios técnicos. Tampoco estas decisiones escapan al control jurídico ${ }^{41}$. La revisión jurisdiccional, eso sí, sólo puede hacerse cuando los errores o los defectos en la valoración técnica sean ostensibles o manifiestos ${ }^{42}$.

En la STS de 1 de marzo de 2011, recurso de casación 5864/2008, ponente Antonio Martí García, tras recordar las SSTC 219/2004, de 29 de noviembre, y 39/1983, de 16 de mayo, sobre la discrecionalidad técnica y la tutela judicial efectiva, considera que "no resulta lógico ni razonable" que sin analizar las circunstancias del caso concreto, la Administración rechazase la participación del interesado en las pruebas. El acto de nombramiento para cargos de libre designación es un acto singular dentro de la categoría de actos discrecionales, no siendo susceptibles de fiscalización en vía jurisdiccional las condiciones subjetivas determinantes de la confianza. El TS, no obstante lo anterior, ha anulado numerosos nombramientos de directores generales por no estar justificados. Considera necesaria la justificación "objetiva y concreta”. Niega que se cumpla con dicho requisito simplemente con "consideraciones abstractas o genéricos juicios de valor" (STS 3 de septiembre de 2010). La STS de 29 de septiembre de 2006, recurso de casación 155/2003, Ponente José Díaz Delgado, considera que la relación de confianza sólo puede apreciarla la autoridad que verifica el nombramiento, "sin estar sometida al requisito formal de hacer una exposición de los motivos en virtud de los cuales prefiere a determinada persona respecto a otra u otras". Véase la STS 15 de noviembre de 2011, que anula el sistema de nombramiento por libre designación de coordinadores, asesores, analistas y responsables del Principado de Asturias (confirma STSJ Asturias de 22 de junio de 2009). Insiste el TS en el carácter excepcional de la libre designación, y en la necesidad de justificar y motivar caso por caso por qué debe utilizarse. La STS 21 de diciembre 2011, recurso de casación 4081/2010, ponente José Díaz Delgado, confirma la Sentencia que había anulado la relación de puestos de trabajo de la Junta de Andalucía en relación con los puestos de libre designación, insistiendo en la necesidad de especial motivación por la Administración. El Consejo de Estado francés, en resolución de 23 de diciembre de 2011, ha anulado un nombramiento por error manifiesto de apreciación de las aptitudes de la persona designada. Pacteau, B., “Nomination au choix du gouvernement et erreur manifeste d'appréciation. Note sous Conseil d'État, 23 décembre 2011, Syndicat parisien des administrations centrales, n. ${ }^{\circ} 346629$ ", en RFDA 2012, p. 115 y siguientes. Allí se recuerda que el nombramiento, muy libre y a menudo politizado, de personas para altos puestos de la Administración francesa, es fiscalizable por el Consejo de Estado, como ya había reconocido en anteriores resoluciones (por ejemplo en el caso Bleton de 1988). El control de las aptitudes de los designados, pese a todo, se limita al error manifiesto.

40 Véase la STS 21 de diciembre de 2010, ponente José Díaz Delgado. A la falta de motivación cuando en ocasiones la Adminstración emplea modelos formulario en materia de dependencia se han referido entre otras muchas, las STSJCV, Sentencia 199/2011, de 9 de marzo; STSJCV 674/2010, de 17 de noviembre; STSJCV 624/2010, 9 de noviembre; STSJCV 294/2010, de 5 de mayo; STSJCV 208/2010, de 17 de marzo.

41 Cerulli Irelli, V., Lineamenti del diritto amministrativo, G. Giappichelli Editore, Torino, 2010, p. 289 y siguientes, recuerda que en la doctrina italiana se sostiene que cuando aparecen cuestiones técnicas la Administración no ejerce un poder discrecional propiamente dicho. Como ejemplo de discrecionalidad técnica utiliza el "interés artístico e histórico", que es un juicio técnico (que implica la utilización de conocimentos históricos, artísticos, arqueológicos...), o el juicio técnico que hay que hacer para saber si se han producido "graves irregularidades en la administración" de entidades financieras, o "graves pérdidas patrimoniales". Admite, no obstante, que cabe el control de la actuación administrativa en estos casos con la aplicación de las técnicas que se aplican a la discrecionalidad, y muy en particular la razonabilidad de la decisión adoptada. La apreciación de la "belleza del conjunto" por la Administración es una manifestación de la discrecionalidad técnica que puede revisarse si es manifiestamente arbitraria.

42 Piénsese, por ejemplo, en las normas sobre evaluación de los grados de dependencia (art. 27 Ley 39/2006). La composición de los órganos de valoración es esencial, pues emite un juicio técnico que se 
Añadimos la mención a otros principios fundamentales, como el de proporcionalidad $^{43}$, o el de precaución (que ha situado la incertidumbre científica en el corazón del proceso de adopción de decisiones), y nos detenemos mínimamente en el principio de objetividad, pues a partir de la CE de 1978 no hay norma referida a la organización y actividad de las Administraciones públicas que se precie que no recoja expresamente el principio de servicio objetivo a los intereses generales. La objetividad, además, es un principio de actuación impuesto por la Constitución que los Juzgados y Tribunales, en más de una ocasión, han relacionado con el principio de igualdad ${ }^{44}$.

presume válido salvo que se pruebe el error evidente. Rara vez un Tribunal estima el recurso y anula la resolución de grado y nivel. Puede verse, no obstante, la STSJ Extremadura, Sentencia 174/2010, de 26 de febrero. Otras muchas desestiman los recursos, STSJ Extremadura 158/2011, de 24 de febrero, p.o. 346/2009. Sobre la presunción de acierto del dictamen frente al que cabe prueba en contrario puede verse la STSJ Galicia 774/2011, de 6 de julio, r.apelación 715/2010. A la inexistencia de error evidente en los informes técnicos se refiere la STSJ Asturias 1156/10, de 21 de octubre, recurso contencioso-administrativo 1735/2008. A la inexistencia de error evidente también se refiere la STSJ Madrid 1186/2010, de 29 de diciembre. La STSJ Galicia, Sentencia 697/2011, de 22 de junio, r. apelación 783/2010, sostiene que el resultado de la valoración de grado y nivel debe mantenerse salvo error manifiesto. Al carácter técnico del informe también se refiere la. STSJ Madrid 1065/2010, de 3 de diciembre, rec. contencioso-administrativo 503/2009. Véase la STS 6 de junio de 2011, recurso de casación 5668/2008, ponente Manuel Campos Sánchez-Bordona, que declara no haber lugar al recurso de casación interpuesto contra la Sentencia que había desestimado el recurso frente a la denegación por la Administración de una autorización para la realización de obras de acceso a una carretera estatal. Ambas resoluciones coniciden en sostener que "la Administración puede, pues, por razones de interés público como son las de mantener la máxima seguridad en la circulación vial, variar o desplazar las conexiones de acceso a las carreteras estatales así como alterar tanto las características físicas como la situación de los accesos a las carreteras estatales, incluso con el desplazamiento del punto kilométrico en que se producirá la conexión". Se recuerda, además, la STS de 12 de febrero de 2001 que sostuvo "la seguridad vial requiere atribuir a la Administración un margen de discrecionalidad de modo que, en cada caso, pueda determinar lo más conveniente para el mejor tránsito de la vía, en función de factores como la variabilidad de la intensidad del tráfico, la velocidad permitida y la naturaleza de la carretera, entre otros".

43 Puede verse sobre la proporcionalidad de la sanción, entre una bibliografía inabarcable, Wilhelm von Humboldt, Ideen zu einem Versuch, die Grenzen der Wirksamkeit des Staates zu begrenzen, (1792), cito aquí por Los límites de la acción del Estado, Estudio preliminar, traducción y notas de Joaquín Abellán, Tecnos, Madrid, 2009. Muñoz Machado, S., Tratado de Derecho administrativo..., cit., p. 558 y siguientes, recuerda la doctrina del TC sobre la previsibilidad de las sanciones, debe librarse a los ciudadanos del temor a ser sancionados "por conductas cuya tipificación no está clara, y depende de actos aplicativos singulares de la Administración (SSTC 133/1987, 101/1988, 93/1992, 120/1996)”.

44 Puede verse el artículo 3.1 de la Ley 30/1992, de 26 de noviembre, de Régimen Jurídico de las Administraciones Públicas y del Procedimiento Administrativo Común, los artículos 2.1, 3.2.f) y 4 de la Ley 6/1997, de 14 de abril, de Organización y Funcionamiento de la Administración General del Estado, el artículo 6 de la Ley 7/1985, de 2 de abril, de Bases del Régimen Local o, en el ámbito europeo, el artículo 9 del Código europeo de buena conducta administrativa. El artículo 8.3 de la Ley 38/2003, de 17 de noviembre, General de Subvenciones, exige que la "gestión de las subvenciones" se realice de acuerdo con los principios de "publicidad, transparencia, concurrencia, objetividad, igualdad y no discriminación”. El artículo 17.3.e) de la misma Ley, dice que la norma reguladora de las bases de concesión de las subvenciones concretará los "criterios objetivos de otorgamiento de la subvención y, en su caso, ponderación de los mismos”. El artículo 20 de la Ley 7/2007, EBEP, remite prácticamente en blanco al desarrollo autonómico la evaluación de la conducta y del desempeño de funciones por los empleados públicos pero exigie que dicha evaluación se adecue a "criterios de transparencia, objetividad, imparcialidad y no discriminación". Santamaría Pastor, J.A., Principios de Derecho administrativo general l, lustel, Madrid, segunda edición, pp. 82-83 considera que la objetividad implica un doble orden de exigencias (la prohibición de la desviación de poder, definida en el artículo 70.2 LRJCA, y la ponderación de todos los intereses en juego previa a la adopción de 
El alcance y los límites del control judicial, la intromisión del Poder Judicial en asuntos que algunos pueden entender que no le corresponden, es el verdadero problema de fondo y, casi estamos plenamente convencidos, en la práctica resulta irresoluble.

\subsection{El alcance del control jurisdiccional}

La posición que distingue entre conceptos jurídicos indeterminados (que sólo admiten una única solución justa), y actos discrecionales, se sostiene en numerosas sentencias del Tribunal Supremo. Es perfectamente comprensible, desde luego, que los jueces y magistrados opten por distinguir entre conceptos jurídicos indeterminados y discrecionalidad, pues la amplitud del control jurisdiccional varía significativamente ${ }^{45}$.

todas las decisiones administrativas). Este principio, además, opera como parámetro de valoración jurídica de toda la actuación administrativa. A las Administraciones, que tienen carácter servicial, se les impone un deber de neutralidad en su actuación. El artículo 103.1 CE impone la neutralidad de la actuación administrativa, y el artículo 103.3 CE la actuación imparcial de sus servidores, que no están sometidos al Gobierno de turno. Sobre la ética en la función pública se ha escrito mucho. En Ureña Salcedo, J. A., "Comentario a los artículos 86 a 88. Deberes y código de conducta de los empleados públicos.”, en Comentarios a la Ley de función pública valenciana, Tirant lo blanch, Valencia, en prensa cuando se redacta este trabajo, puede encontrarse una breve referencia bibliográfica a estas cuestiones. Valga aquí con citar Carro Fernández-Valmayor, J.L., "Ética pública y normativa administrativa", RAP, 181, enero-abril 2010; Al servizio della Nazione. Etica e statuto dei funzionari pubblici, a cura di Francesco Merloni e Roberto Cavallo Perin, Franco Angeli s.r.l., Milano, 2009; Muñoz Machado, S., "Notas sobre la libertad de opinión y la actividad política de los funcionarios públicos” REDA, n. ${ }^{\circ}$ 11, octubre-diciembre 1976. La Administración es una organización profesionalizada que, al menos en teoría, selecciona a sus servidores conforme a criterios objetivos de mérito y capacidad y no de preferencia política. A la falta de objetividad en la ponderación de méritos y en la evaluación del rendimiento, con vulneración del principio de igualdad, se han referido numerosas sentencias del Tribunal Supremo. Véase la STS de 13 de julio de 2011, recurso de casación 4964/2007, ponente Nicolás Maurandi Guillén, o la STS de 21 de diciembre de 2011, recurso de casación 2477/2010, ponente José Díaz Delgado. Afirma el TS que los Tribunales pueden "basándose en las pruebas practicadas, especialmente la pericial, anular o sustituir las valoraciones del Tribunal Calificador, cuando se demuestra en el proceso que aquellas son incorrectas y contrarias a los principios antes citados, pudiendo valerse el recurrente de cuantas pruebas en derecho sean admisibles. En consecuencia, la presunción de legalidad, (propia por lo demás de todos los actos administrativos), queda desvirtuada por la prueba procesal correspondiente". También puede verse la STS 13 de febrero de 2012, recurso de casación 2354/2009, ponente José Díaz Delgado, que insiste en que "la prueba pericial es el único medio de que dispone el interesado para demostrar que el acto resolutorio de un proceso selectivo es contrario a derecho". Entiende que denegar dicha prueba "produce indefensión al recurrente, pues a través de la misma puede demostrar el error del Tribunal Calificador (...) que no goza de una potestad infiscalizable jurisdiccionalmente". En este caso ordena la "retroacción de actuaciones a la vía administrativa, para que se proceda a un nuevo examen del ejercicio práctico del recurrente, previo establecimiento de los criterios de puntuación, y con asignación concreta de la valoración que a cada miembro del Tribunal le merecen las distintas respuestas emitidas". La STS 21 de diciembre de 2011, recurso de casación 5807/2010, ponente José Díaz Delgado, casa la sentencia y condena a la Administración demandada a declarar al recurrente apto y su derecho a acceder al cuerpo con efectos desde la fecha en que debió ser nombrado por la Administración.

45 La discusión viene de lejos. Cicerón, De Officiis..., cit., p. 226, recuerda la dificultad para resolver los pleitos en que había que valorar la buena fe. Se pregunta “¿quiénes son los buenos? ¿qué es obrar bien? He aquí la gran cuestión. Tanto es así que Quinto Escévola, el pontífice máximo decía que había una grave y delicada responsabilidad en aquellos arbitrajes en los que se aplica la expresión "según la buena fe", fórmula que tenía una larga extensión y debía aplicarse en las tutelas, en las sociedades, en los depósitos, en los manda- 
No podemos detenernos en el detalle de los vaivenes que ha sufrido en nuestro país la doctrina de la discrecionalidad y los conceptos jurídicos indeterminados. Basta con apuntar ahora que aunque una parte importante de la doctrina llegase a defender la desaparición de la discrecionalidad administrativa para reconducir todo el fenómeno a los conceptos jurídicos indeterminados, estamos de acuerdo con el Profesor Muñoz Machado cuando afirma que existen conceptos de experiencia que remiten a la apreciación de los hechos (en los que cabe una única solución), pero también se emplean conceptos en las normas que implican juicios de valor, juicio técnicos o políticos en los que la libertad de la Administración aparece con toda crudeza ${ }^{46}$.

Para los Profesores García de Enterría y Tomás-Ramón Fernández, con cita de importantes resoluciones judiciales, si al final del proceso contencioso-administrativo puede concluirse que hay una única solución en el caso concreto, "es absolutamente inevitable que el juez lo reconozca así e incorpore al fallo esa única solución ya posible, porque así lo impone la lógica más elemental y así lo exige, en fin, el derecho fundamental a una tutela judicial efectiva y plena que reconoce y garantiza el artículo 24 de la Constitución". El Derecho público, como recordase el Profesor García de Enterría, no pretende eliminar la política, que es libertad de opciones, simplemente intenta ponerle algunos límites a la actuación administrativa ${ }^{47}$. Si al final del proceso

tos, en las compras, en las ventas, en los arriendos y alquileres, actos sin los cuales no podría existir la sociedad de la vida. Agregaba que era propio de un juez habilísimo el establecer la obligación de cada una de las partes, sobre todo porque en la mayoría de los casos hay acciones directas contrarias". Puede verse, entre muchas otras resoluciones judiciales, la STS de 27 de abril de 2009, recurso de casación 2901/2005, donde se reconoce el derecho al recurrente a obtener la nacionalidad española. Dice expresamente que la "buena conducta cívica constituye, según jurisprudencia constante, un concepto jurídico indeterminado, lo que significa sencillamente que la Administración carece de discrecionalidad en esta materia". La STS de 18 de mayo de 2009, recurso de casación 3261/2005, sostiene que las "circunstancias excepcionales" que permiten a la Administración dispensar del requisito de residencia en España para recuperar la nacionalidad española, "no configura una potestad discrecional de la Administración (...) concurriendo esas circunstancias la Administración no puede negarse a la exención". Entiende el TS que no tratándose de discrecionalidad sino de la aplicación de un concepto jurídico indeterminado "podemos adentrarnos en el corazón de la decisión administrativa para comprobar que responde a la voluntad del legislador, definida en la norma de forma difusa o imprecisa, pero que sólo admite una única solución justa en cada caso". Bocanegra Sierra, R., Huergo Lora, A., "Un paso...", cit., p. 407, destacan su extrañeza ante las SSTS que sostuvieron que los nombramientos para cargos judiciales y fiscales no necesitaban ser motivados porque no eran decisiones discrecionales sino que se limitaban a aplicar un concepto jurídico indeterminado como el de "candidato más idóneo", con lo que por primera vez la distinción entre discrecionalidad y conceptos jurídicos indeterminados sirve, precisamente, para negar el deber de motivación y reducir así el control judicial.

46 Muñoz Machado, S., Tratado de Derecho administrativo..., cit., p. 542 y siguientes, analiza el desarrollo de la doctrina de los conceptos jurídicos indeterminados, recuerda que no hace demasiado se sostuvo la desaparición de la categoría de la discrecionalidad, entre otras cosas porque el interés general es un concepto indeterminado. Insiste en que existen conceptos de experiencia que remiten a la apreciación de los hechos, pero también conceptos que implican juicios de valor, técnicos o políticos, con lo que vuelve a aparecer la discrecionalidad. Sánchez Morón, M., "Artículo 103 CE", cit., p. 1684, menciona las SSTC 26/1981, 27/1989, 233/1997, y 296/2006. Muñoz Machado, S., "Conceptos jurídicos indeterminados", voz en Diccionario de Derecho administrativo, lustel, p.553, recuerda la distinción entre el núcleo de los conceptos y su halo, y pone numerosos ejemplos de anulación de las decisiones de la Administración por los Tribunales "cuando no se acomodan a la interpretación justa de los conceptos indeterminados".

47 García de Enterría, E., "La Administración pública y la Ley", REDA 108, octubre-diciembre 2000, que recoge el texto de la intervención del autor en el Instituto Europeo de Administración Pública de Maas- 
"son posibles varias soluciones, todas ellas lícitas y razonables, únicamente la Administración podrá decidir al respecto” ${ }^{48}$.

El derecho a la tutela judicial efectiva del artículo $24 \mathrm{CE}$, en fin, ha justificado que se limitasen al máximo las inmunidades del poder, que se limitasen las decisiones exentas de control judicial ${ }^{49}$.La tutela judicial efectiva, sin embargo, no puede suponer la sustitución de la decisión de Gobierno o de la Administración "en la determinación de los aspectos propiamente políticos o técnicos de sus decisiones” ${ }^{50}$, según se deduce, además, del tenor literal del artículo 71.2 de la Ley 29/1998, que impide que los Tribunales determinen tanto la forma en que han de quedar redactados los preceptos reglamentarios como el contenido discrecional de los actos anulados. Puede que en algunos casos la retroacción de actuaciones sea la única solución posible.

\section{LA MOTIVACIÓN DE LAS DECISIONES DE LA ADMINISTRACIÓN Y LA DISCRECIONALIDAD JUDICIAL}

A modo de conclusión ofrecemos al lector una última invitación a la reflexión, que resulta inevitable tras haber planteado unas líneas más atrás el alcance del control judicial de la actividad administrativa discrecional. Es indiscutible que en los últimos 40 años se ha avanzado mucho en nuestro país en el control de la discrecionalidad administrativa ${ }^{51}$. La labor del legislador (exigiendo a la Administración la motivación de sus

tricht, al recibir en noviembre de 1999 el premio Alexis de Tocqueville. Habría que recordar, por lo demás, que son los propios políticos los que aprueban esas normas que imponen límites a su actuación. El milagro del Derecho administrativo al que se refirió Weil.

48 García de Enterría, E., Fernández Rodríguez, T.-R, Curso de Derecho..., cit., pp. 474-475.

49 Díez Picazo, L. M. a, Sistema de Derechos fundamentales, Aranzadi, Thomson-Civitas, Cizur Menor (Navarra), 2008, p. 425, recuerda que el derecho de acceso a los tribunales se reconoce como derecho fundamental en las constituciones de la segunda mitad del s. XX, y que en España antes de la Constitución de 1978, como viene apuntándose en este trabajo, había no pocas actuaciones de la Administración exentas de control judicial. Lógicamente relaciona el derecho de acceso a los tribunales con la legitimación para impugnar, "el derecho de acceso a los tribunales sólo desaparece cuando no existe un interés mínimamente personalizado". Sobre el principio pro actione y el contencioso-administrativo (p. 430) recuerda las fundamentales SSTC 14/2006, y 186/2006, sobre el plazo para recurrir el silencio administrativo. Apunta, lógicamente, que el derecho a la tutela judicial efectiva comprende "el derecho a obtener una resolución motivada sobre el fondo de la solicitud dirigida al órgano judicial” (p. 431).

50 Sánchez Morón, M., Derecho administrativo..., cit., p. 107. Giannini, Il potere discrezionale della pubblica amministrazione, Giuffrè, Milano, 1939. Cito aquí por las líneas que pueden encontrarse en "Potere amministrativo e discrezionalità”, en Sabino Cassese, Massimo Severo Giannini, Laterza, Roma-Bari, 2010, p. 129.

51 Fernández Rodríguez, T.-R., Del arbitrio..., cit., p. 16, afirma que "toda la Historia del Derecho Público se explica (...) como un lento y laborioso proceso de reducción del poder a la razón, a las razones del Derecho”. En la p. 121, insiste en que lo importante es la legitimidad que otorga el inexcusable razonamiento, "que lo respalde en cada caso a la vista de las concretas circunstancias que concurran en el mismo". Añade en la p. 122 que "sin motivación suficiente, esto es, sin justificación bastante, no hay arbitrio legítimo, sino arbitrariedad pura y simple”. Fernández Rodríguez, T.-R., “Arbitrariedad y discrecionalidad...", cit., "la cuestión no es ir más lejos, sino marchar más seguro y no quedar a expensas de ninguna política jurisprudencial”, (p. 5), que también se refirió, no obstante, a la "reducción a cero de la discrecionalidad" en la aplicación del concepto jurídico indeterminado en el caso concreto (p. 13 y siguientes). Muñoz Machado, S., Tratado de Derecho administrativo..., cit., p. 552 y siguientes, apunta las últimas reaccio- 
actos), la autolimitación de la propia Administración (reduciendo la discrecionalidad en el caso concreto) y la importante labor desarrollada jueces y magistrados, sin olvidar el importante esfuerzo doctrinal, tienen mucho que ver en ello ${ }^{52}$.

Una de las líneas de avance del Derecho administrativo, no obstante lo anterior, sigue siendo la necesidad de imponer mayor transparencia en la actuación administrativa. Hay que continuar recordando la obligación que pesa sobre la Administración de exponer las razones, los motivos por los que actúa de un determinado modo. La motivación de las decisiones administrativas sigue siendo el caballo de batalla en esta materia. Se ha avanzado mucho, desde luego, pero siguen existiendo ámbitos de actuación administrativa que se caracterizan por la discrecionalidad más absoluta ${ }^{53}$.

Esa amplia libertad de la Administración y la desmesurada extensión de sus poderes ejecutivos ha sido denunciada en infinidad de ocasiones. Igual que están sustituyéndose algunas autorizaciones o licencias por declaraciones responsables y controles administrativos ex post, podría revisarse si determinadas medidas para ser ejecutadas por la Administración, ante la oposición de los interesados a cumplir voluntariamente, deberían ser autorizadas por los jueces. La pluralidad y la confusión de intereses, la difícil ponderación de intereses en el caso concreto a la que nos referíamos en las primeras líneas de este trabajo, también podría avalar esta solución.

El margen de libertad de los jueces también existe (y en algunos países, al menos en determinadas épocas, éstos han interpretado ese margen muy ampliamente ${ }^{54}$ ). La

nes a lo que denomina "excesos de control jurisdiccional", ante "la sustitución de las decisiones administrativas por decisiones judiciales". Insiste tanto en que "no hay límites constitucionales al control jurisdiccional” como en”la imperiosa necesidad de someter a criterios más rigurosos la creación jurisprudencial del Derecho".

52 Ibidem, p. 563 y siguientes, se refiere a la autovinculación administrativa y a algunos de sus intrumentos (el soft law de planes, programas, instrucciones, etcétera). Puede pensarse, del mismo modo, en la autolimitación de tribunales de acceso al empleo público detallando los criterios que constan en las bases, o en la concreción de los criterios para la adjudicación de un contrato.

53 Véase la concesión directa de ayudas prevista en el artículo 22.2.c) de la Ley 38/2003, que utiliza numerosos conceptos jurídicos indeterminados ("se acrediten razones de interés público, social, económico o humanitario, u otras debidamente justificadas que dificulten su convocatoria"). En la STS de 23 de noviembre de 2011, recurso de casación 3638/2009, ponente María Isabel Perelló Doménech, sobre denegación de la ayuda solicitada por incentivos regionales, recuerda que en esta materia sigue reconociéndose a la Administración "amplias facultades de apreciación de las circunstancias concurrentes", y "ante la limitación de medios económicos" corresponde exclusivamente a la Administración valorar las diferentes propuestas presentadas. "En esta valoración cuenta la Administración con una discrecionalidad que sólo puede ser revisada jurisdiccionalmente en casos de arbitrariedad o manifiesto error". En algunos casos los Tribunales siguen afirmando que la Administración no tiene que justificar sus decisiones. Véase, aunque en ningún caso se habla de discrecionalidad, la STS de 7 de diciembre de 2011, por la que se fija doctrina legal en relación a la comprobación del valor de inmuebles por la Administración. La Administración "no viene obligada a justificar previamente que el valor asignado para la tasación de las fincas hipotecadas coincide con el valor ajustado a la base imponible del impuesto, ni la existencia de algún elemento de defraudación que deba corregirse".

54 En Cicerón, De Officiis..., cit. p. 74, puede leerse que "algunas injusticias provienen también del engaño y de una interpretación demasiado sutil y maliciosa al propio tiempo del derecho. De forma que ya es corriente el proverbio: la extema justicia es injusticia extrema". Como se hace notar al pie de página, se 
reacción doctrinal ante los excesos judiciales, sea o no por la distinción entre conceptos jurídicos indeterminados y discrecionalidad, o por el amplio margen que la aplicación de los principios generales del Derecho ofrece a los jueces y magistrados, también resulta bien conocida 55 . Los últimos decenios, al menos los administrativistas, están poniendo el acento en la discrecionalidad judicial más que en la discrecionalidad administrativa. Es perceptible una llamada a la autolimitación de los jueces y, en todo caso a la motivación de sus decisiones ${ }^{56}$.

\section{BIBLIOGRAFÍA CITADA}

Alli Aranguren, J.-C., La construcción del concepto de Derecho administrativo español, Thomson-Civitas, Cizur Menor (Navarra), 2006.

Arjona Sebastiá, C., Los votos discrepantes del juez O. W. Holmes, lustel, Madrid, 2006. Baño León, J. M. ${ }^{a}$, Los límites constitucionales de la potestad reglamentaria (Remisión normativa y reglamento independiente en la Constitución de 1978), Civitas-Servicio de Publicaciones Facultad de Derecho de la Universidad Complutense, 1991.

Baño León, J. M. a , Derecho urbanístico común, lustel, Madrid, 2009.

Bocanegra Sierra, R., Huergo Lora, A., "Un paso atrás en el control judicial de la discrecionalidad: su confusión con los conceptos jurídicos indeterminados y la dispensa del deber de motivar", REDA, 111, julio-septiembre 2011.

Carro Fernández-Valmayor, J.L., "Ética pública y normativa administrativa”, RAP, 181, enero-abril 2010.

trata de la expresión summum ius summa iniuria, "el proverbio ha llegado a nosotros citándose con las palabras de Cicerón, incluso por personas no muy conocedoras del latín”.La creación del Derecho por los jueces es abiertamente reconocida en algunos sistemas, y curiosamente negada en otros. El mismo Cicerón, p. 122, ya apuntaba que eran los magistrados los que definían el contenido de los derechos. La importante labor del Consejo de Estado francés y de otros Tribunales en la creación del Derecho administrativo resulta bien conocida. Sobre la evolución de la lex mercatoria, o el ius mercatorum, puede verse, entre muchos otros, Galgano, F., Lex mercatoria, II Mulino, Bologna, quinta edición,2010. La reflexión sobre la creación y la destrucción del derecho por los jueces en el sistema norteamericano, con un sistema difuso de control de constitucionalidad de las leyes, puede encontrarse en Tocqueville, A., De la démocratie en Amérique (1835). Cito por la edición de Gallimard del año 2000, en particular el capítulo VI de la primera parte del Libro I, bajo la rúbrica "Du pouvoir judiciaire aux Etats-Unis, et de son action sur la société politique", p. 164 y siguientes, que se refiere al poder político de los jueces norteamericanos. Algunos ejemplos concretos pueden verse en Lambert, E., Le gouvernement des juges et la lutte contre la législation sociale aux États-Unis (1921). Cito por El gobierno de los jueces, Estudio preliminar de Luis Pomed,Tecnos, Madrid, 2010. Arjona Sebastiá, C., Los votos discrepantes del juez O. W. Holmes, lustel, Madrid, 2006. También puede verse NIETO, A., El arbitrio judicial, Ariel, Barcelona, 2000.

55 Baste con recordar aquí la referencia del Profesor Fernández Rodríguez, T.-R., Del arbitrio y de la arbitrariedad judicial, lustel, Madrid, 2005, p. 95, a la "arbitrariedad suma" de algunos jueces y magistrados en la elección de los hechos que fundamentan la decisión. Admite, lógicamente, que la respuesta no es idéntica en todos los órdenes jurisdiccionales y que la clave reside, en cualquier caso, en la motivación. Insiste en la p. 115 en que "el control de la discrecionalidad debe ser siempre un control negativo, respetuoso con la libertad concedida por la Ley a la autoridad a la que ésta ha otorgado el poder de decidir".

56 Tanquerel, Th., “La pesée des intérêts vue par le juge administratif”, en La pesée globale des intérêts. Droit de l'environnement et de l'aménagament du territoire”, Charles-Albert Morand (ed.), Helbing et Lichtenbahn, Bâle et Francfort-sur-le-Main, 1996. 
Cerulli Irelli, V., Lineamenti del diritto amministrativo, G. Giappichelli Editore, Torino, 2010. Cicerón, De Officiis, Sobre los deberes, traducción, introducción y notas de José GuiIlén Cabañero, Alianza editorial, Madrid, 2001.

Constant, B., Principes de politique applicables à tous les governements représentatifs et particulièrement à la Constitution actuelle de la France (1815), Cito aquí por Escritos políticos,estudio preliminar, traducción y notas de María Luisa Sánchez Mejía, Centro de Estudios Constitucionales, Madrid, 1989.

Díez Picazo, L. M. a Sistema de Derechos fundamentales, Aranzadi, Thomson-Civitas, Cizur Menor (Navarra), 2008.

Duguit, L., Les transformations du Droit Public, Librairie Armand Colin, Paris, 1913. Cito aquí por la edición de La Mémoire du Droit, 1999.

Embid Irujo, A., "La relación entre los poderes del Estado en la reciente dogmática alemana”, RAP, n. ${ }^{\circ} 115$, enero-abril, 1988.

Esteve Pardo, J., “La revisión judicial de las decisiones de las autoridades reguladoras. Jurisprudencia del Tribunal Supremo y la Audiencia Nacional”, en Derecho de la regulación I. Fundamentos e instituciones de la regulación, Muñoz Machado, S, Esteve Pardo, J., (directores), lustel, Madrid, 2009.

Esteve Pardo, J., Lecciones de Derecho administrativo, Marcial Pons, Madrid, 2011.

Fernández Rodríguez, T.R., "Arbitrariedad y discrecionalidad en la doctrina jurisprudencial constitucional y administrativa”, Revista General de Derecho Administrativo, n. ${ }^{\circ}$, diciembre de 2003.

Fernández Rodríguez, T.R., Del arbitrio y de la arbitrariedad judicial, lustel, Madrid, 2005.

Fernández Rodríguez, T.R., "Sobre los límites constitucionales del poder discrecional”, RAP, 187, enero-abril 2012.

Flückiger, A., “L'essor des actes étatiques incitateurs: le glas de la loi?”, Législation et Evaluation, 2001/1.

Flückiger, A, "Régulation, dérégulation, autorégulation: I'emergence des actes etatiques non obligatoires", Révue de droit suisse, 2/2004.

Gabarda, O., "Vers la généralisation de la motivation obligatoire des actes administratifs? Enjeux et perspectives d'évolutions autour du principe de la motivation facultative", RFDA 2012.

Galgano, F., Lex mercatoria, II Mulino, Bologna, quinta edición,2010.

García de Enterría, E., Fernández Rodríguez, T.-R, Curso de Derecho administrativo, vol. I, Civitas, Madrid, 1997.

García de Enterría, E., “La Administración pública y la Ley”, REDA 108, octubre-diciembre 2000.

García de Enterría, E., “La interdicción de la arbitrariedad en la potestad reglamentaria", RAP, n. ${ }^{\circ}$ 30, septiembre-diciembre 1959.

García-Pelayo, M., Los mitos políticos, Alianza Editorial, Madrid, 1981.

Giannini, Il potere discrezionale della pubblica amministrazione, Giuffrè, Milano, 1939. Cito aquí por "Potere amministrativo e discrezionalità", en Sabino Cassese, Massimo Severo Giannini, Laterza, Roma-Bari, 2010.

Humboldt, Wilhelm von, Ideen zu einem Versuch, die Grenzen der Wirksamkeit des Staates zu begrenzen (1792), Los límites de la acción del Estado, Estudio prelimi78 nar, traducción y notas de Joaquín Abellán, Tecnos, Madrid, 2009. 
Lambert, E., Le gouvernement des juges et la lutte contre la législation sociale aux ÉtatsUnis (1921). Cito por El gobierno de los jueces, Estudio preliminar de Luis Pomed, Tecnos, Madrid, 2010.

Leguina Villa, J., “Artículo 106.1 El control judicial de la Administración pública”, en Comentarios a la Constitución Española, XXX aniversario, María Emilia Casas Baamonde y Miguel Rodríguez-Piñero y Bravo-Ferrer (Directores), Fundación Wolters Kluwer, Madrid, 2009.

Locke, J., The Second Treatise of Civil Government. An Essay Concerning the True Original, Extent and End of Civil Government, (1690). Cito por Segundo Tratado sobre el Gobierno Civil. Un ensayo acerca del verdadero origen, alcance y fin del Gobierno Civil, traducción, prólogo y notas de Carlos Mellizo, Alianza Editorial, Madrid, quinta reimpresión 2008.

Mathieu, B., La loi, Dalloz, Paris, 2004, 2. ${ }^{\text {a edición. }}$

Merloni, F., Cavallo Perin, R. (directores), Al servizio della Nazione. Etica e statuto dei funzionari pubblici, Franco Angeli s.r.l., Milano, 2009.

Mill, John Stuart, Considerations on Representative Government, (1861). Cito aquí por Consideraciones sobre el gobierno representativo, traducción y prólogo de Carlos Mellizo, Alianza Editorial, Madrid, 2001.

Mill, John Stuart, On Liberty. Cito aquí por Sobre la libertad, traducción Pablo de Azcárate, Alianza Editorial, 2009.

Moor, P., Droit admnistratif, vol. II Les actes administratifs et leur contrôle, Staempfi Editions, Berne, 2002.

Morand, Charles-Albert (ed), L'Etat propulsif. Contribution à l'étude des instruments d'action de L'Etat", Publisud, Paris, 1991.

Morand, Charles-Albert, "La légalité de la légalité”, en Figures de la légalité, Publisud, Paris, 1992.

Morell Ocaña, L., "La objetividad de la Administración pública y otros componentes de la ética de la institución”, REDA 111, 2011.

Muñoz Machado, S., "Notas sobre la libertad de opinión y la actividad política de los funcionarios públicos" REDA, n. ${ }^{\circ} 11$, octubre-diciembre 1976.

Muñoz Machado, S., "Las concepciones del Derecho administrativo y la idea de participación en la Administración”, RAP, n. ${ }^{\circ}$ 84, septiembre-diciembre 1977.

Muñoz Machado, S., Tratado de Derecho administrativo y Derecho público general, vol. I, lustel, 2. ${ }^{a}$ edición, 2006, reimpresión 2009.

Muñoz Machado, S., “Conceptos jurídicos indeterminados”, voz en Diccionario de Derecho administrativo, lustel,

Nieto, A., El arbitrio judicial, Ariel, Barcelona, 2000.

Nieto, A, El desgobierno de lo público, Ariel, Barcelona, 2008.

Nieto, A, Derecho administrativo sancionador, Tecnos, Madrid, 1994, 2. ${ }^{\text {a edición. }}$

Nieto, A, "La Administración sirve con objetividad los intereses generales", Estudios sobre la Constitución española. Homenaje al Profesor Eduardo García de Enterría, T. III, Civitas, Madrid, 1991.

Ortega, L., De la Sierra, S., (coords.), Ponderación y Derecho Administrativo, Marcial Pons, Madrid, 2009. 
Pacteau, B., "Nomination au choix du gouvernement et erreur manifeste d'appréciation. Note sous Conseil d'État, 23 décembre 2011, Syndicat parisien des administrations centrales, n. ${ }^{\circ}$ 346629, en RFDA 2012.

Parada Vazquez, R., Derecho administrativo I, Parte General, decimoquinta edición, Marcial Pons, Madrid, 2004.

Rousseau, J.-J., Du Contrat Social (1762), edición de Pierre Burgelin, Garnier-Flammarion, Paris, 1966.

Sánchez Morón, M., Derecho administrativo. Parte General, Tecnos, Madrid, quinta edición, 2009.

Sánchez Morón, M., “Artículo 103 CE”, en en Comentarios a la Constitución Española, XXX aniversario, María Emilia Casas Baamonde y Miguel Rodríguez-Piñero y Bravo-Ferrer (Directores), Fundación Wolters Kluwer, Madrid, 2009.

Santamaría Pastor, J.A., Principios de Derecho administrativo general I, lustel, Madrid, segunda edición, 2009.

Tanquerel, Th., "La pesée des intérêts vue par le juge administratif”, en La pesée globale des intérêts. Droit de l'environnement et de l'aménagament du territoire", Charles-Albert Morand (ed.), Helbing et Lichtenbahn, Bâle et Francfort-sur-leMain, 1996.

Tocqueville, A., De la démocratie en Amérique (1835). Cito por la edición de Gallimard, 1961, reedición en folio histoire del año 2000.

Tocqueville, A., L'ancien régime et la Révolution (1856). Cito aquí por la edición de J.-P. Mayer, Éditions Gallimard, 1967, reedición en folio histoire 2009.

Travi, A., Lezioni di Giustizia Amministrativa, G. Giappichelli Editore, Torino, 2010.

Ureña Salcedo, J. A., "Comentario a los artículos 86 a 88. Deberes y código de conducta de los empleados públicos.", en Comentarios a la Ley de función pública valenciana, Tirant lo blanch, Valencia, en prensa.

Ureña Salcedo, J. A., "Las cláusulas sociales en la contratación administrativa”, en Libertades económicas, mercado de trabajo y derecho de la competencia, J.M. ${ }^{a}$ Goerlich (director), Consejo Económico y Social, Colección estudios, n. ${ }^{\circ} 230$, Madrid, 2011.

Ureña Salcedo, J. A., “Comentario al artículo 130 de la Constitución. El Estado Social y los mandatos a los poderes públicos", en Comentarios a la Constitución Española, XXX aniversario, María Emilia Casas Baamonde y Miguel Rodríguez-Piñero y Bravo-Ferrer (Directores), Fundación Wolters Kluwer, Madrid, 2009.

Ureña Salcedo, J. A, "Las novedades introducidas en la organización administrativa estatal por la Ley Orgánica 3/2007", en Comentarios a la Ley Orgánica 3/2007, de 22 de marzo, para la lgualdad efectiva de mujeres y hombres; Tomás Sala Franco, María Amparo Ballester Pastor, José María Baño León, José Miguel Embid Irujo, José María Goerlich Peset (coordinadores), La Ley- Wolters Kluwer España SA, Las Rozas, 2008. 